\title{
Synthesis and characterization of novel oxazines and demonstration that they specifically target cyclooxygenase 2
}

\author{
V. Srinivas ${ }^{a, \dagger}$, Chakrabhavi Dhananjaya Mohan ${ }^{\mathrm{b}, \dagger}$, C. P. Baburajeev ${ }^{\mathrm{a}, \dagger}$, Shobith Rangappa ${ }^{\mathrm{c}}$, \\ Swamy Jagadish $^{\text {b }}$, Julian E. Fuchs ${ }^{\mathrm{d}}$, Alexey Yu. Sukhorukov ${ }^{\mathrm{e}}$, Chandra ${ }^{\mathrm{f}}$, Daniel J. Mason ${ }^{\mathrm{d}}$, \\ Kothanahally Shivaramu Sharath Kumar ${ }^{b}$, Mahendra Madegowda ${ }^{\mathrm{f}}$, Andreas Bender ${ }^{\mathrm{d}}$, Basappa $^{\mathrm{a}, *}$, \\ Kanchugarakoppal Subbegowda Rangappa ${ }^{\text {b,* }}$

\footnotetext{
${ }^{a}$ Laboratory of Chemical Biology, Department of Chemistry, Bangalore University, Central College Campus, Palace Road, Bangalore 560001, India

${ }^{\mathrm{b}}$ Department of Studies in Chemistry, Manasagangotri, University of Mysore, Mysore 570006, India

${ }^{\mathrm{c}}$ Frontier Research Center for Post-genome Science and Technology, Hokkaido University, Sapporo 060-0808, Japan

${ }^{\mathrm{d}}$ Centre for Molecular Informatics, Department of Chemistry, University of Cambridge, Lensfield Road, CB2 1EW Cambridge, United Kingdom

${ }^{\mathrm{e}}$ N.D. Zelinsky Institute of Organic Chemistry, Leninsky Prospect, 47, Moscow 119991, Russia
} \\ ${ }^{\mathrm{f}}$ Department of Studies in Physics, Manasagangotri, University of Mysore, Mysore 570006, India
}

\section{A R T I C L E I N F O}

\section{Article history:}

Received 10 February 2015

Revised 7 May 2015

Accepted 15 May 2015

Available online 27 May 2015

\section{Keywords:}

COX2

Oxazines

$\mathrm{SCS}-\mathrm{Bi}_{2} \mathrm{O}_{3}$

Proinflammatory disease

\begin{abstract}
A B S T R A C T
In the present study, we used solution combustion synthesis-bismuth oxide $\left(\mathrm{Bi}_{2} \mathrm{O}_{3}\right)$ as catalyst for the simple and efficient synthesis of 1,2-oxazine based derivatives of 6-fluoro-3-(piperidin-4yl)benzo[ $d]$ isoxazoles, 1-arylpiperazine and carbazoles. (4aR,8aR)-4-(4-Methoxyphenyl)-3-((4-(4methoxyphenyl)piperazin-1-yl)methyl)-4a,5,6,7,8,8a-hexahydro-4H-benzo[e][1,2]oxazine was found to be the most potent compound with a high degree of selectivity in inhibition towards COX2 $(1.7 \mu \mathrm{M})$ over COX1 $(40.4 \mu \mathrm{M})$ demonstrating the significance of 1,2-oxazine derivatives in developing COX2 specific inhibitors. Molecular docking analyses demonstrated that an isoleucine residue in the active site of COX1 is responsible for lower affinity to COX1 and increased potency towards COX2. Overall, our study reveals that the new 1,2-oxazine-based small molecules qualify as lead structures in developing COX2specific inhibitors for anti-inflammatory therapy.
\end{abstract}

(c) 2015 Elsevier Ltd. All rights reserved.
Inflammation is a defensive response of the host immune system against harmful antigenic invasion to minimize the deleterious effects. ${ }^{1,2}$ Prolonged infection or delayed elimination of antigens result in the constant triggering of the host immune system which may lead to proinflammatory diseases including cancer, rheumatoid arthritis, atherosclerosis, inflammatory bowel diseases and psoriasis. $^{3-5}$ Therefore, inflammation can rightly be called as double-edged sword. ${ }^{6}$ The comprehensive research in the previous decade has established the role of several proinflammatory mediators in development of aforesaid diseases. The entanglement of cyclooxygenase (COX) as one of the key proinflammatory mediators has been well-demonstrated and found to be the good therapeutic target in treating several proinflammatory diseases. ${ }^{7,8}$ COX1 and COX2 are the two isoforms of cyclooxygenase in which the former is constitutively expressed in normal tissues to maintain homeostasis and latter is renowned to express on cytokine induction in inflammatory cells. ${ }^{9}$ Unfortunately, during chronic inflammation,

\footnotetext{
* Corresponding authors.

$\dagger$ These authors contributed equally to this work.
}

COX2 is overexpressed which leads to exaggerated way of immune response and ultimately results in developing proinflammatory diseases. ${ }^{10}$ Copious efforts are underway to design the inhibitors against COX2 to treat these ailments. Nonsteroidal anti-inflammatory drugs (NSAIDs) such as Celecoxib and Rofecoxib were implemented as inhibitors of COX2 in treating osteoarthritis and rheumatoid arthritis. Recently, patients administered with Rofecoxib were found to be prone to myocardial infarction and thus Celecoxib is now considered a risk with regard to enhancing vascular complications. ${ }^{11}$ Given the relevance with increased adverse effects of existing drugs, there is an immediate need for developing the selective COX2 inhibitors with high specificity and minimal adverse effects to treat proinflammatory diseases.

Oxazine, benzoxazine and isoxazoline derivatives possess wide variety of biological activities including anti-inflammatory, antioxidants, neurosedatory and PI3 kinase inhibition. ${ }^{12-16}$ Furthermore, diaryl heterocycles have been extensively studied as COX inhibitors ${ }^{17}$ and many of COX inhibitors possess 1,2-diaryl substitution on a four to six membered central ring system. In addition, $\mathrm{N}$-substituted phenyl piperidine, phenyl piperizine and carbazole 

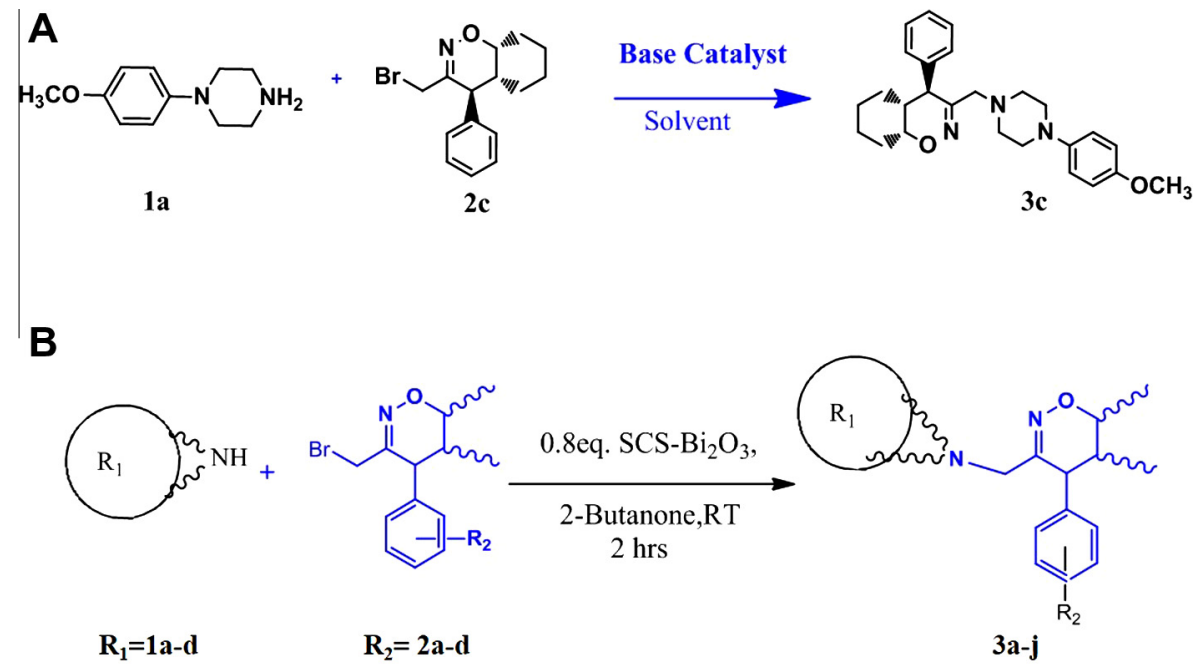

Figure 1. (A) Generalization of the reaction for the synthesis of oxazines. (B) Schematic representation of the title compounds using SCS-Bi $\mathrm{O}_{3}$.

derivatives are proved to possess potent anti-inflammatory activity. Further, carprofen is a propanoic acid conjugated carbazole derivative and non-steroidal anti-inflammatory drug which selectively inhibits COX2 and does not affect COX1 activity. Based on this observation, we rationally designed and synthesized the 1,2oxazine derivatives and probed them against COX1 and COX2. In continuation of our effort to synthesize and explore various pharmacological properties of heterocycles, ${ }^{18-25}$ we herein report the synthesis, characterization and COX2 inhibitory activity of novel 1,2-oxazine-tethered, 6-fluoro-3-(piperidin-4-yl)benzo[d]isoxazoles, 1-arylpiperazine and carbazoles.

Metal oxides emerged as major categories of solid catalysts in the field of organic synthesis. Among the metal oxide catalysts, transition metals occupy a predominant part because of their high activity, easy catalyst separation, long catalytic life, low cost, reusability and selective action. ${ }^{26,27}$ In our previous study, we reported the preparation of combustion derived $\mathrm{Bi}_{2} \mathrm{O}_{3}\left(\mathrm{SCS}-\mathrm{Bi}_{2} \mathrm{O}_{3}\right.$ ) and its application in cross coupling reaction ${ }^{28}$ which emphasize not only on the basic character of $\mathrm{Bi}_{2} \mathrm{O}_{3}$ but also on high surface area which makes it a promising catalyst in organic synthesis.

Initially, $\mathrm{N}$-alkylation reaction was studied on piperazines, piperidines, carbazoles using 3-bromomethyl-phenyl substituted$4 H-[1,2]$ oxazine derivatives. ${ }^{29}$ In the general approach, upon careful observation it was found that using of $\mathrm{K}_{2} \mathrm{CO}_{3}$ as a base can cause the decomposition of 3-bromomethyl 4-phenyl substituted 1,2-oxazines. On the other hand, usage of $\mathrm{Na}_{2} \mathrm{CO}_{3}, \mathrm{NaHCO}_{3}$, $\mathrm{LiOH}, \mathrm{NaOCl}$ end up with incomplete reaction and poor yield. In the present work, we focused our investigation in search of the suitable base which drives the above reaction without affecting the oxazine moiety and explored the possibility of $\mathrm{SCS}-\mathrm{Bi}_{2} \mathrm{O}_{3}$ as base catalyst towards the preparation of new oxazines. For the selection of base-catalyst system and optimization of reaction conditions, the reaction was studied on 1-(4methoxyphenyl)piperazine and 3-(bromomethyl)-4a,5,6,7,8,8a-hexahydro-4-phenyl-4H-benzo[o][1,2] oxazines (Fig. 1A).

On $\mathrm{N}$-alkylation using $\mathrm{Bi}_{2} \mathrm{O}_{3}$ as a base catalyst, we did not observe the cleavage of 3-bromomethyl-4-phenyl substituted$4 H-[1,2]$ oxazine derivatives. However based on the experimental results, in the presence of $\mathrm{SCS}-\mathrm{Bi}_{2} \mathrm{O}_{3}$, the reaction took place effectively in lesser time with better yield (Supplementary Table 1 ). The most robust reaction was achieved by the use of 0.8 equiv of the SCS- $\mathrm{Bi}_{2} \mathrm{O}_{3}$ acts as an effective base catalyst in 2-butanone in the preparation of various piperazines, piperidines, and carbazoles using 3-bromomethyl substituted oxazine derivatives (Fig. 1B).
And newly synthesized novel oxazine molecules are shown in Table 1.

More importantly, the single crystal of $\mathbf{3 i}$ was obtained and the corresponding structure was identified by X-ray crystallographic analysis (Fig. 2) supporting the formation of 1,2-oxazines via $\mathrm{SCS}-\mathrm{Bi}_{2} \mathrm{O}_{3}$ base catalysis. Significant quality of $\mathrm{SCS}-\mathrm{Bi}_{2} \mathrm{O}_{3}$ base catalyst could be recovered and reused. This was investigated with a model reaction of carbazole with 3-(bromomethyl)-4a,5,6,7,8,8ahexahydro-4-phenyl-4H-benzo[e][1,2]oxazine. After each run, catalyst was centrifuged, washed with ethanol, dried in oven and reused in the next run (Supplementary Fig. 1). For five catalytic runs, we observed no considerable loss of the activity of the catalyst and resulted in completion of reaction within $2 \mathrm{~h}$ in $88-86 \%$ conversions against $93 \%$ of the fresh catalyst.

The crystal structure analysis showed that the compound $3 \mathbf{i}$ crystallizes in monoclinic system under the space group $P 2_{1} / c$, with cell parameters $a=18.2847(9) \AA, \quad b=6.0710(4) \AA, \quad c=20.8044(10) \AA$, $\beta=99.789(5)^{\circ}$ and $Z=4$. The bond lengths and bond angles agree with the standard values and are comparable to a related structure. ${ }^{30}$ The heterocyclic oxazine ring adopts a half chair conformation with atoms $\mathrm{N} 16$ and 017 displaced by $0.754(2)$ and $0.317(1) \AA$, respectively, from the mean position. The carbazole and benzoxazine bridged by the carbon atom, makes a dihedral angle of $51.84(9)^{\circ}$. The methoxy phenyl group is in anti-periplanar conformation as indicated by the torsion angle of $179.82(19)^{\circ}$. The crystal structure ( $\mathbf{3 i}$ ) is stabilized by $\mathrm{C}-\mathrm{H}$. . .N intramolecular hydrogen bonds, showing linear chain parallel to the $c$ axis.

1,2-Oxazines selectively inhibits COX2 in vitro: Inflammation is predominantly mediated by arachidonic acid metabolism catalyzed by cyclooxygenase isoforms in various tissues. ${ }^{31}$ Considering the significant role of COX in proinflammatory diseases, we evaluated all the newly synthesized compounds $\mathbf{3 a - j}$ for their ability to inhibit COX1 and COX2 as described previously. ${ }^{32}$ Interestingly, we found that, all the compounds displayed high selectivity towards the inhibition of COX2 over its counterpart indicating that 1,2-oxazines are better antagonists of COX2 (Table 2). Compounds $\mathbf{3 a}, \mathbf{3 b}$ and $\mathbf{3 c}$ are found to be the most potent inhibitors of $\mathrm{COX} 2$ with the $\mathrm{IC}_{50}$ values of $1.7,2.6$ and $1.8 \mu \mathrm{M}$, respectively. Nevertheless, the activity of COX1 remained unaffected up to $35 \mu \mathrm{M}$.

In silico interaction studies: We attempted to retrospectively rationalize the observed experimental affinity and selectivity profile of the oxazine series by performing in silico docking 

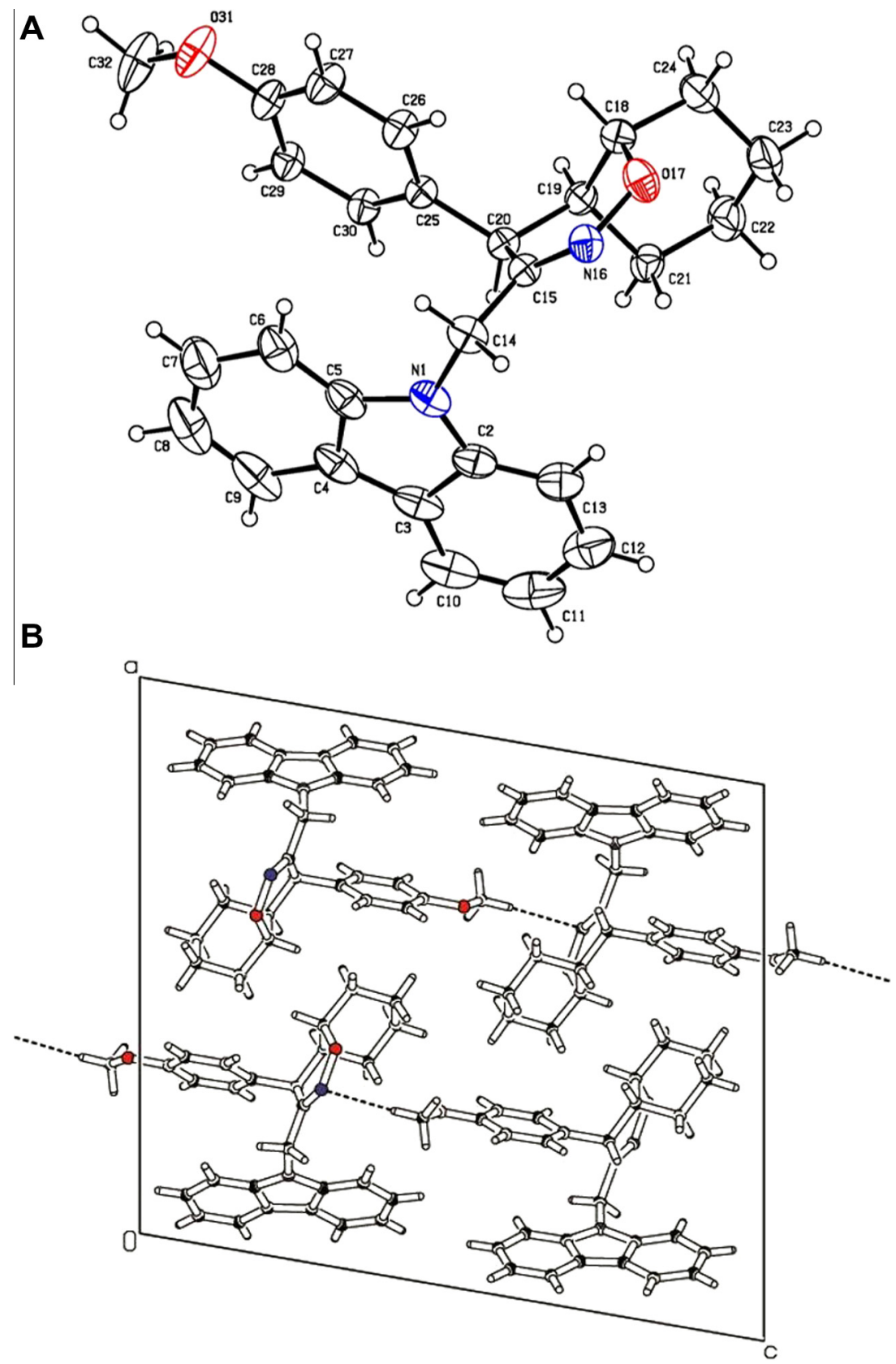

Figure 2. (A) ORTEP diagram of the molecule (3i) at 50\% probability. (B) Packing of the molecule viewed parallel to the $c$ axis. Dotted line represents the hydrogen bonds.

experiments. We observe consistent pose predictions for the whole set of compounds in both binding sites (see Fig. 3 for a representative pose prediction). The hydrophobic ligands mostly form Van der Waals contacts with the receptor, thus pointing towards the importance of shape complementarity of the receptors and ligands. We observed a moderate linear correlation of $r_{\text {Pearson }}=0.73$ between docking scores and experimental $\mathrm{IC}_{50}$ values over the whole data set. Each of the eleven compounds in the set shows more favorable docking scores for COX2 than for COX1 in excellent agreement with experimental data that shows selectivities for COX2 up to factor 24. On a molecular level this can be rationalized by a single difference in amino acid composition V523I between COX1 and COX2 binding sites that is well described in literature. ${ }^{33}$
Here, the COX1 pocket bears an additional methylene group at the Ile residue leading to a reduction in cavity size. As this region of the binding site is consistently occupied by all predicted poses, we attribute the observed differences in binding affinities for our ligands to this steric effect that is expected to decrease affinities of bulky ligands for COX1.

In conclusion, herein we comprehensively report the synthesis and anti-inflammatory potential of 1,2-oxazines mediated via selective inhibition of COX2. Our in silico docking analysis clearly demonstrated that presence of an auxiliary methylene group at the isoleucine in the active site is responsible for poor interaction of oxazines with COX1. Therefore, this report introduces 1,2-oxazines as a new class of selective COX2 inhibitors to treat various proinflammatory diseases. 
Table 1

Yields of the newly synthesized oxazines $\mathbf{3 a}-\mathbf{j}$

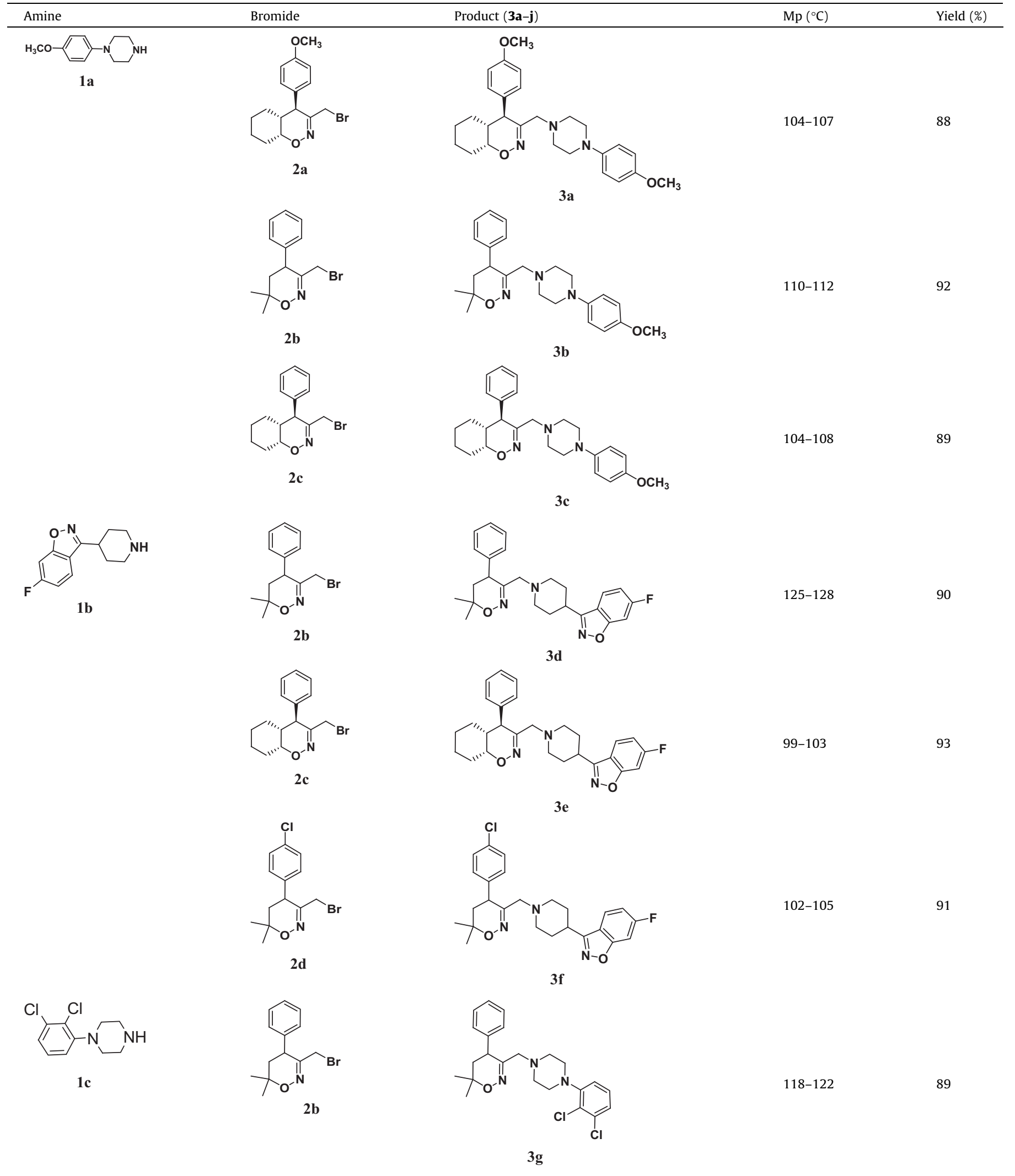


Table 1 (continued)

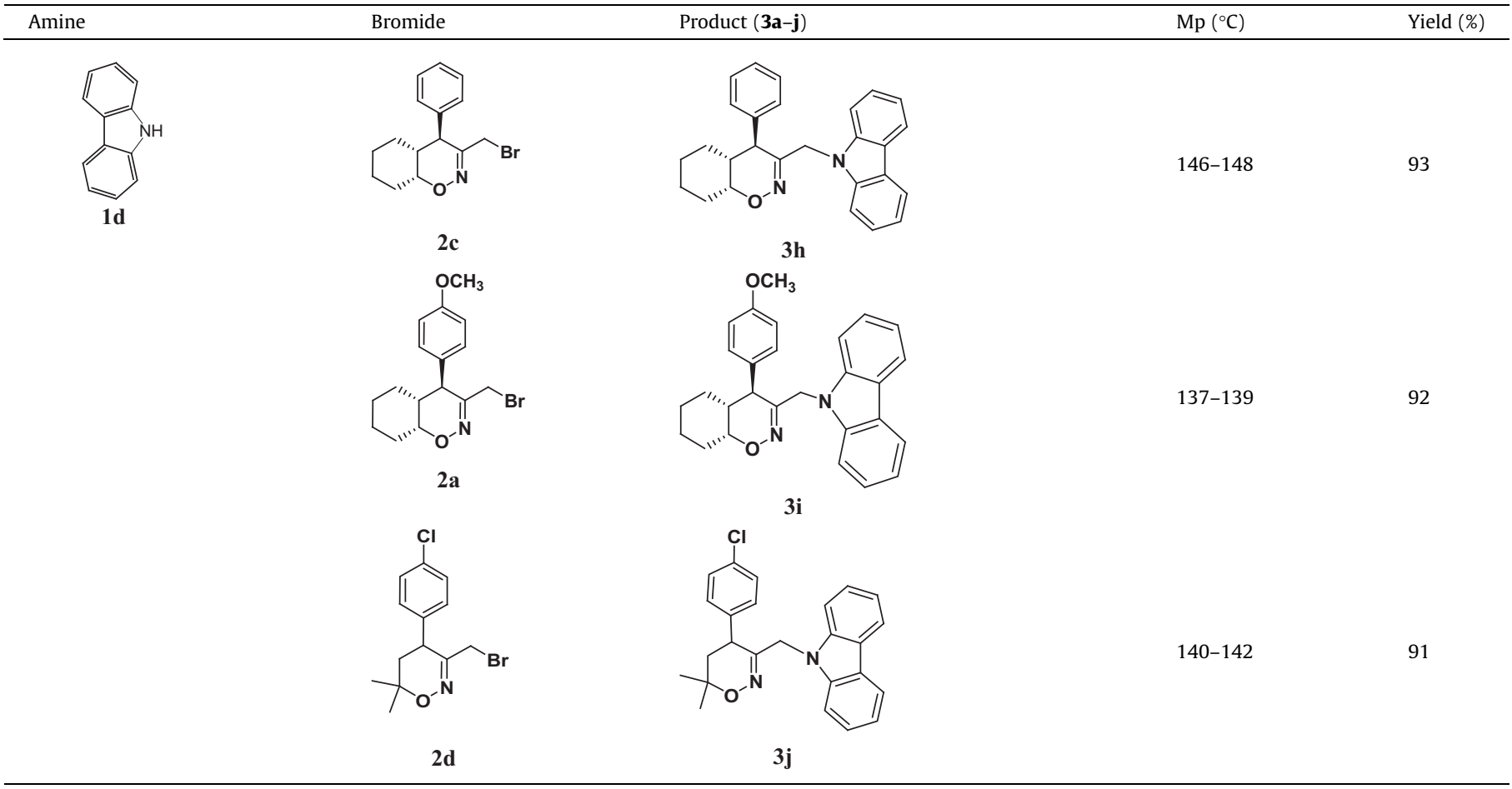

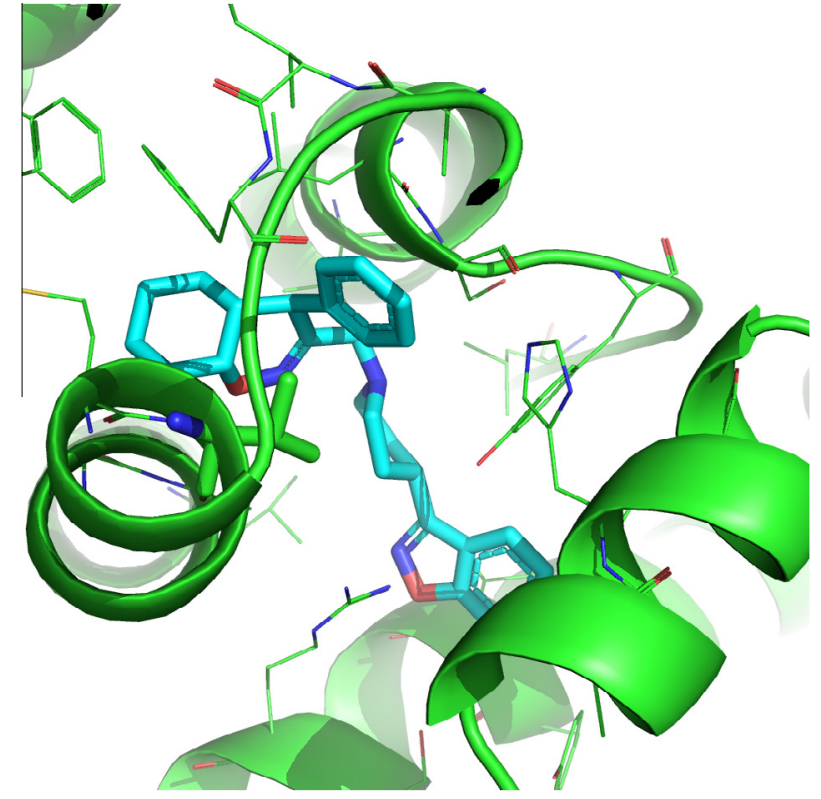

Figure 3. Predicted binding mode of compound 3e to COX2: The protein is shown in semi-transparent green cartoon representation with interface residues to the docked ligand (colored by element with carbons in cyan) highlighted in thin lines (only heavy atoms are shown respectively). COX-1/2 selectivity determining residue V523 (shown in stick representation) is in direct contact with the oxazine scaffold, thus directing binding preferences of the compounds.
Table 2

COX1 and COX2 inhibition assay

\begin{tabular}{lcl}
\hline Title compounds & $\mathrm{COX} 2$ & $\mathrm{COX} 1$ \\
& $\mathrm{IC}_{50}(\mu \mathrm{M})$ & $\mathrm{IC}_{50}(\mu \mathrm{M})$ \\
\hline $\mathbf{3 a}$ & 1.7 & 40.4 \\
$\mathbf{3 b}$ & 2.6 & 50.6 \\
$\mathbf{3 c}$ & 1.8 & 35.8 \\
$\mathbf{3 d}$ & 10.5 & 39.8 \\
$\mathbf{3 e}$ & 4.7 & 42.8 \\
$\mathbf{3 f}$ & 4.1 & 40.1 \\
$\mathbf{3 g}$ & 6.8 & 54.9 \\
$\mathbf{3 h}$ & 9.9 & 59.9 \\
$\mathbf{3 i}$ & 5.9 & 50.8 \\
$\mathbf{3 j}$ & 3.9 & 40.8 \\
Indomethacin & 1.2 & 12.5 \\
\hline
\end{tabular}

\section{Acknowledgments}

This research was supported by University Grants Commission (41-257-2012-SR), Vision Group Science and Technology, Department of Science and Technology (NO. SR/FT/LS-142/2012) to Basappa. K.S.R. thanks DST-JSPS (DST/INT/JAP/P-79/09), DST Indo-Korea [INT/indo-korea/122/2011-12] and DST-PURSE for funding. A. Yu. S. thanks Russian President's Council for Grants for financial support (grant MK-5957.2015.3) and C.D.M. thanks DST for INSPIRE fellowship. 


\section{Supplementary data}

CCDC NO. 1021028-contains the supplementary crystallographic data for the molecule (3i). These data can be obtained free of charge at www.ccdc.cam.ac.uk/conts/retrieving.html [or from the Cambridge Crystallographic Data Centre (CCDC), 12 Union Road, Cambridge CB2 1EZ, UK; fax: +44 (0)1223 762911; email: deposit@ccdc.cam.ac.uk].

Supplementary data (experimental procedures for the synthesis and the pharmacological investigations) associated with this article can be found, in the online version, at http://dx.doi.org/10. 1016/j.bmcl.2015.05.047.

\section{References and notes}

1. Coussens, L. M.; Werb, Z. Nature 2002, 420, 860 .

2. Smith, J. A. J. Leukocyte Biol. 1994, 56, 672.

3. Ricciotti, E.; FitzGerald, G. A. Arterioscler. Thromb. Vasc. Biol. 2011, 31, 986.

4. Hamminga, E.; van der Lely, A. J.; Neumann, H.; Thio, H. Med. Hypotheses 2006, 67, 768.

5. Libby, P.; Ridker, P. M.; Maseri, A. Circulation 2002, 105, 1135.

6. Kurlansky, P. J. Thorac. Cardiovasc. Surg. 2014.

7. Dubois, R. N.: Abramson, S. B.; Crofford, L.; Gupta, R. A.; Simon, L. S.; Van De Putte, L. B.; Lipsky, P. E. FASEB J. 1998, 12, 1063.

8. FitzGerald, G. A. Nat. Rev. Drug Disc. 2003, 2, 879.

9. Flower, R. J. Nat. Rev. Drug Disc. 2003, 2, 179.

10. Kalinski, P. J. Immunol. 2012, 188, 21.

11. Bhala, N.; Emberson, J.; Merhi, A.; Abramson, S.; Arber, N.; Baron, J. A.; Bombardier, C.; Cannon, C.; Farkouh, M. E.; FitzGerald, G. A.; Goss, P.; Halls, H.; Hawk, E.: Hawkey, C.; Hennekens, C.; Hochberg, M.; Holland, L. E.; Kearney, P. M.; Laine, L.; Lanas, A.; Lance, P.; Laupacis, A.; Oates, J.; Patrono, C.; Schnitzer, T. J.; Solomon, S.; Tugwell, P.; Wilson, K.; Wittes, J.; Baigent, C. Lancet 2013, 382, 769.

12. Ansari, N.; Khodagholi, F.; Amini, M.; Shaerzadeh, F. Biochimie 2011, 93, 899.

13. Mantelingu, K.; Sadashiva, M.; Rangappa, K. Indian J. Chem., Sect. B 2004, 43, 1954.

14. Sukhorukov, A. Y.; Nirvanappa, A. C.; Swamy, J.; Ioffe, S. L.; Nanjunda Swamy, S.; Basappa; Rangappa, K. S. Bioorg. Med. Chem. Lett. 2014, 24, 3618.

15. Basappa; Satish Kumar, M.; Nanjunda Swamy, S.; Mahendra, M.; Shashidhara Prasad, J.; Viswanath, B. S.; Rangappa, K. S. Bioorg. Med. Chem. Lett. 2004, 14, 3679.
16. Basappa; Sadashiva, M. P.; Mantelingu, K.; Swamy, S. N.; Rangappa, K. S. Bioorg. Med. Chem. 2003, 11, 4539 .

17. Kim, H. J.; Chae, C. H.; Yi, K. Y.; Park, K. L.; Yoo, S. E. Bioorg. Med. Chem. 2004, 12 1629.

18. Rangaswamy Roopashree, T. R. S.; Swamy Jagadish; Chakrabhavi Dhananjaya Mohan; Kanchugarakoppal Subbegowda Rangappa Lett. Drug Des. Disc. 2014, 11,1143

19. Bharathkumar, H.; Mohan, C. D.; Ananda, H.; Fuchs, J. E.; Li, F.; Rangappa, S. Surender, M.; Bulusu, K. C.; Girish, K. S.; Sethi, G.; Bender, A.; Basappa; Rangappa, K. S. Bioorg. Med. Chem. Lett. 2015, 25, 1804.

20. Keerthy, H. K.; Garg, M.; Mohan, C. D.; Madan, V.; Kanojia, D.; Shobith, R.; Nanjundaswamy, S.; Mason, D. J.; Bender, A.; Basappa; Rangappa, K. S.; Koeffler, H. P. PloS One 2014, 9, e107118.

21. Keerthy, H. K.; Mohan, C. D.; Sivaraman Siveen, K.; Fuchs, J. E.; Rangappa, S.; Sundaram, M. S.; Li, F.; Girish, K. S.; Sethi, G.; Basappa; Bender, A.; Rangappa, K. S. J. Biol. Chem. 2014, 289, 31879.

22. Mohan, C. D.; Bharathkumar, H.; Bulusu, K. C.; Pandey, V.; Rangappa, S.; Fuchs J. E.; Shanmugam, M. K.; Dai, X.; Li, F.; Deivasigamani, A.; Hui, K. M.; Kumar, A. P.; Lobie, P. E.; Bender, A.; Basappa; Sethi, G.; Rangappa, K. S. J. Biol. Chem. 2014, 289, 34296.

23. Neelgundmath, M.; Dinesh, K. R.; Mohan, C. D.; Li, F.; Dai, X.; Siveen, K. S. Paricharak, S.; Mason, D. J.; Fuchs, J. E.; Sethi, G.; Bender, A.; Rangappa, K. S.; Kotresh, O.; Basappa Bioorg. Med. Chem. Lett. 2015, 25, 893.

24. Sadashiva, C.; Chandra, J. N. S.; Kavitha, C.; Thimmegowda, A.; Subhash, M.; Rangappa, K. S. Eur. J. Med. Chem. 2009, 44, 4848.

25. Sugahara, K.; Thimmaiah, K. N.; Bid, H. K.; Houghton, P. J.; Rangappa, K. S. PloS One 2012, 7, e39444.

26. Sonavane, S. U.; Gawande, M. B.; Deshpande, S. S.; Venkataraman, A.; Jayaram, R. V. Catal. Commun. 2007, 8, 1803.

27. Noguera, C. Physics and Chemistry at Oxide Surfaces; Cambridge University Press, 1996.

28. Anusha, S.; Anandakumar, B.; Mohan, C. D.; Nagabhushana, G.; Priya, B. Rangappa, K. S. RSC Adv. 2014, 4, 52181.

29. Sukhorukov, A. Y.; Kapatsyna, M. A.; Yi, T. L. T.; Park, H. R.; Naumovich, Y. A. Zhmurov, P. A.; Khomutova, Y. A.; Ioffe, S. L.; Tartakovsky, V. A. Eur. J. Org. Chem 2014, 2014, 8148 .

30. Klenov, M. S.; Lesiv, A. V.; Khomutova, Y. A.; Nesterov, I. D.; Ioffe, S. L. Synthesis 2004, 1159.

31. Dobrian, A. D.; Lieb, D. C.; Cole, B. K.; Taylor-Fishwick, D. A.; Chakrabarti, S. K. Nadler, J. L. Prog. Lipid Res. 2011, 50, 115.

32. Sathya, R.; Swamy, J.; Ramesh, S.; Dhananjaya, M.; Nanjundaswamy, A.; Bhadraiah, H.; Zameer, F.; Subbaiah, G.; Subbegowda, R. Med. Chem. (Shariqah (United Arab Emirates)) 2014.

33. Huggins, D. J.; Sherman, W.; Tidor, B. J. Med. Chem. 2012, 55, 1424. 